\title{
COMMENTARY
}

\section{The risks and rewards of expanding ICU capacity}

Jeremy M Kahn ${ }^{* 1,2}$

See related research by Kastrup et al., http://ccforum.com/content/16/4/R126

\begin{abstract}
ICU capacity strain is associated with increased morbidity and lost hospital revenue, leading many hospitals to increase the number of ICU beds. However, this approach can lead to inefficiency and waste. A recent report in Critical Care highlights a different approach: creating new service lines for low-risk patients. In this case, the authors staffed a postanesthesia care unit with an intensivist-led care team, resulting in lower hospital costs with no changes in ICU mortality. Although this type of change carries some risks, and will not work for every hospital, it is an example of the creative solutions hospitals must sometimes undertake to maintain the supply of critical care in response to a rising demand.
\end{abstract}

A recent report in Critical Care demonstrates the types of steps hospitals are taking to address the growing problem of ICU capacity constraints [1]. These steps are often necessary, as ICU strain leads to serious, real-world problems. For example, both admission delays from the emergency department to the ICU and premature discharges from the ICU to the ward are associated with increased mortality $[2,3]$. Moreover, although the data are mixed, new evidence suggests that when ICUs are strained, patients in the ICU experience a greater risk of death [4]. Full ICUs can also affect a hospital's bottom line. Cancelling high-risk elective surgeries due to a lack of appropriate postoperative care means less revenue at a time when many hospitals are struggling financially [5].

Clearly the stakes are high. When faced with ICU capacity constraints, however, hospitals have a limited number of options. The first, and perhaps most obvious, option is to simply add more ICU beds. Hospitals are taking this approach in the United States, where the

*Correspondence: kahnjm@upmc.edu

2Department of Health Policy \& Management, University of Pittsburgh, Scaife Hall

Room 602-B, 3550 Terrace Street, Pittsburgh, PA 15221, USA

Full list of author information is available at the end of the article number of ICU beds is increasing over time [6]. However this approach is misguided at best and harmful at worst hospitals vary in the degree to which they use intensive care without much variation in outcome, suggesting that many ICU patients do not really benefit from ICU-level care [7]. Additionally, increasing the number of ICU beds increases the hospitals fixed costs while at the same time creating waste in the system during times when the ICU is not full [8].

Another option is to create alternative levels of care within the hospital for moderate-risk patients who may not need the ICU. These alternatives can take the form of step-down units for patients in recovery [9] or, as demonstrated by Kastrup and colleagues, expanded postanesthesia care units (PACUs) that can care for intermediate risk, short-stay patients [1]. The benefits of these approaches are that they increase ICU capacity more efficiently than simply adding ICU beds, since these types of beds are cheaper to maintain. As a case in point, in Kastrup and colleagues' study the hospital case mix index - a measure of hospital efficiency related to the average cost per case - increased from 0.286 to 0.309 , indicating a lower cost per case and, presumably, higher operating margins. At the same time, length of stay in the ICU increased - probably due to both removal of shortstay postoperative patients from the denominator and a lack of bed pressure to discharge patients earlier in their treatment course.

Although at first glance this move appears to have been a good one for the hospital, it is worth noting several caveats that could cause efforts like these to backfire. First, increasing ICU capacity by shuttling some postoperative patients through the PACU could just result in more low-risk patients being admitted from the ward [10]. This effect would increase the cost of care for these patients, negating other cost savings. Second, this move presupposes that an intensivist and trained ICU nurses are available to staff the PACU. In many health systems, a shortage of trained ICU staff might make this type of staffing change impossible [11].

In addition to these caveats, Kastrup and colleagues' study has some noteworthy limitations. The case mix index is a crude measure of hospital efficiency, and actual costs, charges and margins are not reported. Also, this 
was a single-center, before-after study that did not control for severity of illness. At least some of these changes are probably due to differences in severity of illness on admission and routine temporal trends, rather than due to the staffing change itself.

Despite these limitations, Kastrup and colleagues' study provides important lessons about the risks and rewards of expanding ICU capacity. Providing highquality critical care in the era of capacity constraints requires creative solutions. Adding more ICU beds is conceptually easy but is also costly and inefficient. Developing new service lines that can care for intermediate-risk patients is more efficient, but is only of value in some circumstances. For example, the highintensity PACU approach of Kastrup and colleagues will not work for ICUs with low numbers of postoperative patients or for ICUs that only care for extremely highrisk surgery patients that almost always require ICU admission. Finally, we must remember that much of ICU utilization is overuse - many patients, especially those at very high risk of death, would not want intensive care at their end of life [12]. Addressing capacity constraints purely by adding capacity, rather than working to prevent overuse, may be a missed opportunity to better align care with patient preferences. Otherwise we risk making changes that are purely about improving the bottom line, rather than about improving care for our patients.

Abbreviations

PACU, post-anesthesia care unit.

\section{Competing interests}

The author declares that he has no competing interests.

\section{Author details}

${ }^{1}$ Clinical Research, Investigation and Systems Modeling of Acute IIIness (CRISMA) Center, Department of Critical Care Medicine, Department of Critical
Care Medicine, University of Pittsburgh, 3550 Terrace Street, Pittsburgh, PA 15261, USA. ${ }^{2}$ Department of Health Policy \& Management, University of Pittsburgh, Scaife Hall Room 602-B, 3550 Terrace Street, Pittsburgh, PA 15221, USA.

Published: 21 September 2012

\section{References}

1. Kastrup M, Seeling M, Barthel S, Bloch A, le Claire M, Spies C, Scheller M, Braun $\mathrm{J}$ : Effects of intensivist coverage in a post-anaesthesia care unit on surgical patients' case mix and characteristics of the intensive care unit. Crit Care 2012, 16:R126

2. Forero R, McCarthy S, Hillman K: Access block and emergency department overcrowding. Crit Care 2011, 15:216.

3. Goldfrad C, Rowan K: Consequences of discharges from intensive care at night. Lancet 2000, 355:1138-1142.

4. Halpern SD: ICU capacity strain and the quality and allocation of critical care. Curr Opin Crit Care 2011, 17:648-657.

5. Kim S, Horowitz I, Young KK, Buckley TA: Analysis of capacity management of the intensive care unit in a hospital. Eur J Oper Res 1999, 115:36-46.

6. Halpern NA, Pastores SM: Critical care medicine in the United States 2000 2005: an analysis of bed numbers, occupancy rates, payer mix, and costs. Crit Care Med 2010, 38:65-71.

7. Chen LM, Render M, Sales A, Kennedy EH, Wiitala W, Hofer TP: Intensive care unit admitting patterns in the veterans affairs health care system. Arch Intern Med 2012, 172:1220-1226.

8. Terwiesch C, Diwas KC, Kahn JM: Working with capacity limitations: operations management in critical care. Crit Care 2011, 15:308.

9. Subbe CP, Criner GJ, Baudouin SV: Weaning units: lessons from North America? Anaesthesia 2007, 62:374-380.

10. Wunsch H, Angus DC, Harrison DA, Collange O, Fowler R, Hoste EA, de Keizer NF, Kersten A, Linde-Zwirble WT, Sandiumenge A, Rowan KM: Variation in critical care services across North America and Western Europe. Crit Care Med 2008, 36:2787-2793, e1-e9.

11. Angus DC, Kelley MA, Schmitz RJ, White A, Popovich J, Jr: Caring for the critically ill patient. Current and projected workforce requirements for care of the critically ill and patients with pulmonary disease: can we meet the requirements of an aging population? JAMA 2000, 284:2762-2770.

12. Earle CC, Landrum MB, Souza JM, Neville BA, Weeks JC, Ayanian JZ: Aggressiveness of cancer care near the end of life: is it a quality-of-care issue? J Clin Oncol 2008, 26:3860-3866.

doi:10.1186/cc11491

Cite this article as: Kahn JM: The risks and rewards of expanding ICU capacity. Critical Care 2012, 16:156. 